\title{
Application of Single Neuron Adaptive PID Approach in Rolling Tension Control
}

\author{
Xiao-dan Zhang ${ }^{1, a}$, Yan-ming Cheng ${ }^{1, b} *$,Yu-xiang $\mathrm{HaO}^{1, \mathrm{c}}$ \\ 1 Beihua University, Jilin, China \\ ${ }^{*}$ Corresponding author
}

Key words: Neuron, PID, Rolling tension control

\begin{abstract}
.
Rolling tension control is an important factor to ensure the quality of steel products. In actual production process, there are shortcomings such as large overshoots, long adjustment time and the parameters are difficult to adjust in real time because rolling tension model is a high-order nonlinear system when conventional PID controller is used to control the tension. In this paper, a single neuron adaptive PID tension control method is proposed. The experimental results show that compared with traditional PID controller, single neuron adaptive PID controller is used to shorten the adjustment time of the tension control to $3 \% \sim 10 \%$, full realization of zero static error is achieved and the robustness of the system is obviously enhanced.
\end{abstract}

\section{Introduction}

The control object selected in this paper is composed of the mechanical of four-stand cold rolling mill, which consists of uncoiler, four rolling mills and crimping machines.

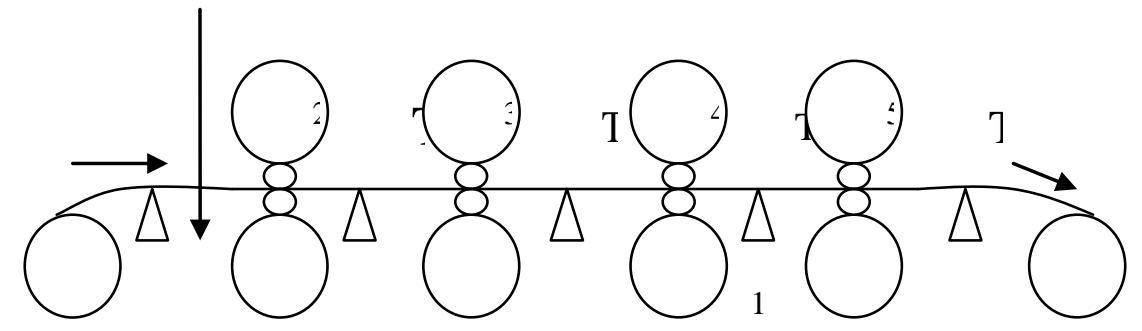

Figure 1 Four-stand cold rolling mill structure

In it, 1: uncoiler, 2-5: first to fourth mill, 6: crimping machine, 7-11: tension meter, 12: pickling and washing, $\mathrm{T}_{1} \mathrm{~T}_{4}: 1,2$ mill, 2, 3 mill, 3, 4 mill, and the tension between 4 mills and crimps.

Tension control is a key issue in continuous production process, especially for strip cold rolling mill. In particular, the control precision of strip tension has a great influence on the rolling stability and the quality of finished strip. For example, the tension between the two racks increases, and its change will reduce the rolling force of the second rack. Torque increases, forward slip decreases and speed decreases reduce the first rack rolling force and increase forward slip value, and it may also affect the crew's other rack technological parameters change. In rolling process, the tension's mutual influence role can be said to "pull the whole body", so tension problem is the core of rolling process. In view of the characteristics of tension control in rolling process, the identification, modeling, and adaptive control of neural network in the system has the following characteristic [1]:

(1) Strong non-linear mapping ability, which can approximate any complex nonlinear relationship.

(2) High degree of self-learning and self-organizing ability to learn and adapt to the dynamic 
characteristics of severe uncertain systems; connections between neurons are diversified, the connection strength between the neurons are of plasticity, which is equivalent to changes in synaptic transmission information capability so that the network can be self-organized through learning and training to meet the requirements of different information processing.

(3) The parallel processing of information makes it have the ability to carry out a large number of operations; network units can make similar process, and the entire network information processing is large-scale parallel.

(4) Simple structure with good robustness and high reliability.

(5) Associative memory and fault tolerance; the storage of information within the neural network is stored in many neurons by content distribution, and each neuron stores part of the information. Each part of the network has the equipotential effect on the storage of information, and the loss of some information can still be restored from the complete information.

Therefore, this paper puts forward the control of rolling tension by combining traditional PID control and neural network.

\section{Single neuron adaptive PID controller principle}

PID controller. In analog control system, the most commonly used control law of controller is PID control. PID controller is a linear controller [3], which constitutes a control error according to the given value $\mathrm{r}^{\mathrm{r}(\mathrm{t})}$ and the actual output value $\mathrm{c}(\mathrm{t})$. Deviation proportion (P), integral (I) and derivative (D) form the control quantity by linear combination to control the controlled object, so it is called PID controller. Its control law is

$$
u(t)=K_{p}\left[e(t)+\frac{1}{T_{I}} \int_{0}^{t} e(t) d t+T_{D} \frac{d e(t)}{d t}\right]
$$

$K_{p}$ is scale factor; $T_{I}$ is integral time constant; $T_{D}$ is derivative time constant.

B. Single neuron adaptive PID controller

Single neuron adaptive PID controller's block diagram [2,4] is shown in Figure 2.

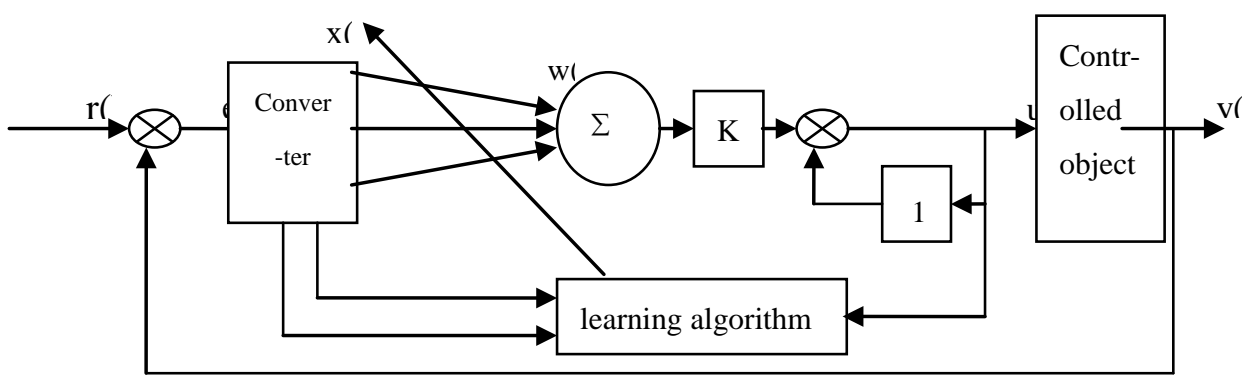

Figure 2 Neuron adaptive PID control system

In Figure 2, the converter input reflects the state of the controlled process and control set, set $r(k)$ the set value, $y(k)$ the output value, the values $x_{1}(k), x_{2}(k), x_{3}(k)$ of the required state which are controlled by converted by single neuron learning got by the converter are,

$$
\left\{\begin{array}{c}
\mathrm{x}_{1}(\mathrm{k})=\mathrm{e}(\mathrm{k}) \\
\mathrm{x}_{2}(\mathrm{k})=\mathrm{e}(\mathrm{k})-\mathrm{e}(\mathrm{k}-1) \\
\mathrm{x}_{3}(\mathrm{k})=\mathrm{e}(\mathrm{k})-2 \mathrm{e}(\mathrm{k}-1)+\mathrm{e}(\mathrm{k}-2)
\end{array}\right.
$$


$\mathrm{w}_{\mathrm{i}}(\mathrm{k})$ is the weighting coefficient corresponding to $\mathrm{X}_{\mathrm{i}}(\mathrm{k}) ; \mathrm{K}$ is the proportion coefficient of neurons, $\mathrm{K}>0 . \mathrm{e}^{\mathrm{e}(\mathrm{k})}=\mathrm{r}(\mathrm{k}) \quad$ - $\mathrm{y}(\mathrm{k})$, is the output deviation at time $\mathrm{k}$. The neurons generate a control signal by an association search

$$
\mathrm{u}(\mathrm{k})=\mathrm{K} \sum_{\mathrm{i}=1}^{3} \mathrm{w}_{\mathrm{i}}(\mathrm{k}) \mathrm{x}_{\mathrm{i}}(\mathrm{k})+\mathrm{u}(\mathrm{k}-1)
$$

The adaptive function of single neuron PID controller is realized by changing the weight $\omega_{\mathrm{i}}$. Learning algorithm is adjusting the weight rule. It is the core of single neuron PID controller and reflects its learning ability. The learning algorithm is as follows:

$$
\omega_{\mathrm{i}}(\mathrm{k}+1)=\omega_{\mathrm{i}}(\mathrm{k})+\eta \mathrm{z}(\mathrm{k})
$$

In it, $\mathrm{z}(\mathrm{k})$ is the learning signal decreasing with the process, $\eta>0$ is the learning rate.

Neural network PID controller mainly corrects weighting coefficient through output deviation so as to realize the purpose of adaptive and self-organizing control. The main operation [4] is divided into:

(1) Parameter initialization. Parameters of single neuron adaptive PID controller are given any of the initial values for controlling at the beginning of the program. The parameters of the next time are adjusted according to output deviation and learning algorithm of the controlled system.

(2) Generate a control signal ${ }^{\mathrm{u}(\mathrm{k})}$. Through single neuron and PID controller, generate control signal $\mathrm{u}(\mathrm{k})$ to control the controlled object and output signal $\mathrm{y}(\mathrm{k})$.

(3) Calculate output deviation $\mathrm{e}(\mathrm{k})$. The output error $\mathrm{e}(\mathrm{k})$ is calculated by the given input value and the feedback output value $\mathrm{y}^{\mathrm{(k})}$ in use of adjusting the weighting factor.

(4) Adaptive adjustment weighting factor $\mathrm{w}_{\mathrm{i}}(\mathrm{k}+1)$. The output deviation $\mathrm{e}(\mathrm{k})$ (or performance index function $\mathrm{J}_{1}$ and $\mathrm{J}_{2}$ ) is generated by feedback, and $\mathrm{W}_{\mathrm{i}}(\mathrm{k}+1)$ is got by adjusting $\mathrm{e}(\mathrm{k}$ ) (or performance index function $\mathrm{J}_{1}$ and $\mathrm{J}_{2}$ ) and weight $\mathrm{w}_{\mathrm{i}}(\mathrm{k})$.

(5) Termination condition judgment. If the termination condition is satisfied (the minimum error criterion is satisfied), the output signal at this time is the optimal solution output, and the calculation is terminated; otherwise, go to step (2) and continue to adjust the weight.

\section{Rolling tension control model}

In this paper, the mathematic model of tension in cold tandem mill is deduced and generated based on the view that tension is produced by adjacent racks' speed difference. $\mathrm{i}$ and $\mathrm{i}+1$ are the two racks adjacent to the tandem mill; $\mathrm{L}$ is the spacing between adjacent racks; $\mathrm{V}_{\text {ih }}$ is the exit speed of the $\mathrm{i}$-th rack strip, and $\mathrm{V}_{(\mathrm{i}+1) \mathrm{h}}$ is the inlet speed of the $\mathrm{i}+1$ rack strip ; rolling direction is from 
left to right, which is shown in Figure 3.

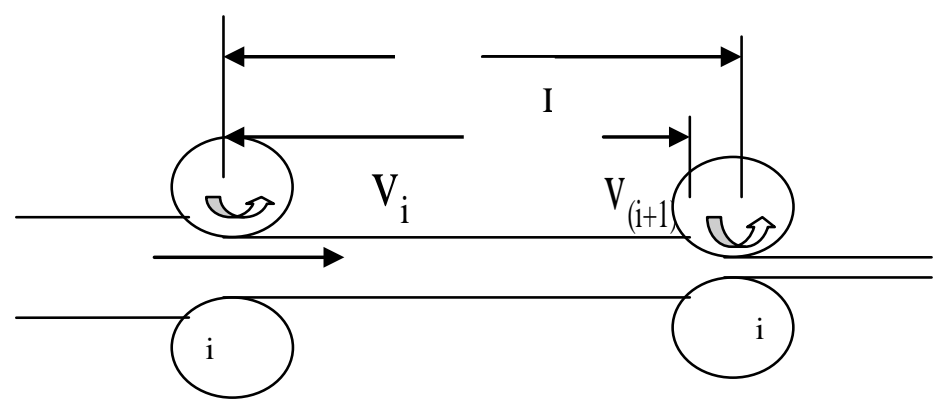

Figure 3 Rolling tension model

Set $\mathrm{V}_{(\mathrm{i}+1) \mathrm{h}}$, then the length of the work piece will be elongated

$\Delta \mathrm{L}=\mathrm{L}^{-\mathrm{L}^{\prime}}$

In it, $\mathrm{L}$ is the length after elongation (m); $\mathrm{L}$ 'is the original length of the strip (m); $\Delta \mathrm{L}$ is the amount of elongation (m).

The relative elongation $\Sigma_{\text {can }}$ be expressed as:

$\sum=\frac{\Delta \mathrm{L}}{\mathrm{L}^{\prime}}=\frac{\Delta \mathrm{L}}{\mathrm{L}-\Delta \mathrm{L}}$

The change rate in relative elongation is:

$\frac{\mathrm{d} \sum}{\mathrm{dt}}=\frac{\left(1+\sum\right)^{2}}{\mathrm{~L}}\left(\mathrm{v}_{(\mathrm{i}+1) \mathrm{h}}-\mathrm{v}_{\mathrm{ih}}\right)$

In normal rolling state, tension deformation generated by the speed is elastic deformation, so this deformation obeys Hooke's law:

$\sum=\frac{\mathrm{T}}{\mathrm{E}}$

In the formula, $\mathrm{E}$ is elastic modulus (Mpa); $\mathrm{T}$ is tension value $(\mathrm{N})$

When $\mathrm{T} / \mathrm{E}<<1$, there is

$\frac{\mathrm{dT}}{\mathrm{dt}}=\frac{\mathrm{E}}{\mathrm{L}}\left(\mathrm{v}_{(\mathrm{i}+1) \mathrm{h}}-\mathrm{v}_{\mathrm{ih}}\right)$

Assuming that $\mathrm{v}_{(\mathrm{i}+1) \mathrm{h}}$ is not affected by slippage amount, and the influence of the slippage is attributed to the change of $\mathrm{V}_{\mathrm{ih}}$, the formula in complex frequency domain is,

$$
\frac{\mathrm{T}(\mathrm{s})}{\mathrm{v}_{(\mathrm{i}+1) \mathrm{h}}(\mathrm{s})-\mathrm{v}_{\mathrm{ih} 0}(\mathrm{~s})}=\frac{\frac{\mathrm{E}}{\mathrm{L}}}{\frac{E v_{\mathrm{i}} \mathrm{a}}{\mathrm{L}}+\mathrm{s}}=\frac{\frac{1}{\mathrm{v}_{\mathrm{i}} \mathrm{a}}}{1+\frac{\mathrm{L}}{\mathrm{Ev}_{\mathrm{i}} \mathrm{a}} \mathrm{s}}
$$

In the formula, $\mathrm{V}_{\mathrm{ih} 0}(\mathrm{~s})$ is the strip exit speed of the $\mathrm{i}$-th rack at $-\mathrm{T}=0$. 
If the double closed-loop system is represented by I type system, the transfer function of the whole control link can be expressed as

$$
\mathrm{G}_{0}(\mathrm{~s})=\frac{\mathrm{k}_{1}}{\mathrm{~s}\left(\tau_{1} \mathrm{~s}+1\right)} \frac{\varepsilon \mathrm{k}_{2}}{\tau_{2} \mathrm{~s}+1}
$$

In the actual system, the structure and parameters of the double closed-loop system are fixed, and the variable parameters of the controlled system are $\varepsilon, \mathrm{k}_{2}$ and $\tau_{2}$.

In it, $, \mathrm{k}_{2} \in(2 \sim 3), \tau_{2} \in(0.1 \sim 0.4), \varepsilon$ is a constant. According to Literature [10], take $k_{2}=2.5$, $\tau_{2}=0.2, \varepsilon=1, \mathrm{k}_{1=1}, \tau_{1}=0.2$, then

$$
G_{0}(s)=\frac{1}{s(0.15 s+1)} \frac{2.5}{0.2 s+1}
$$

After discretization (sampling time 0.1s), then $y(k)=2.9168 y(k-1)-2.8369 y(k-2)+0.92 y(k-3)+0.0000136 u(k-1)+0.00005328 u(k-2)+0.0000135 u(k-3)$

\section{Simulation results}

Conventional PID controller. The initial parameters are: scale coefficient: 10, integral coefficient: 10, differential coefficient: 3 . The simulation curve (simulation time 15s) got is shown in Figure 4 (a). It can be seen that the response is very slow, so we should increase the scale coefficient: scale coefficient: 30, integral coefficient: 10, differential coefficient: 3 . The simulation curve (simulation time 15s) is shown in Figure 4 (b):

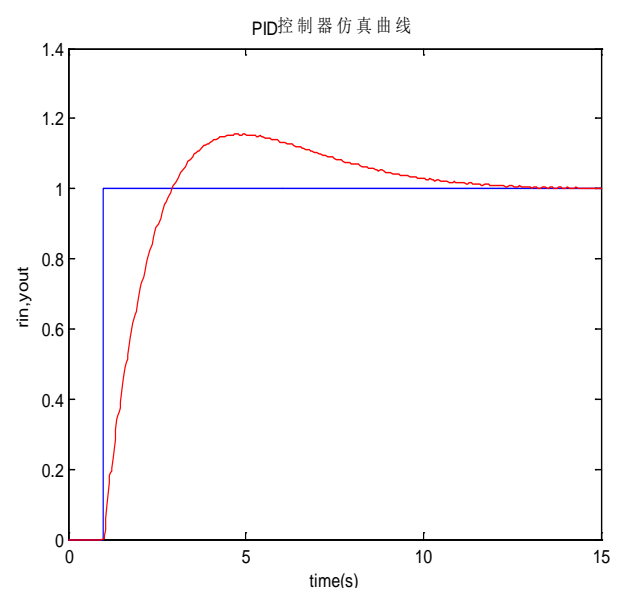

(a)

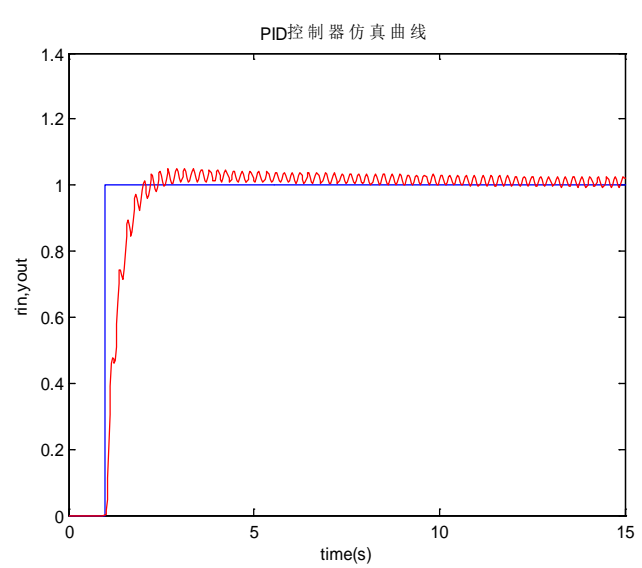

(b)

Figure 4 Simulation diagram of the conventional PID controller

Although the simulation curve is ultimately stable at a given value, zigzag fluctuation occurs due to the instability of the system due to large scale coefficient. So continue adjusting, reduce scale factor, and reduce corresponding integral coefficient to reduce the overshoot and adjust the differential coefficient. The simulation curve is still not ideal.

Simulation of single neuron adaptive PID controller. The simulation results of single neuron adaptive PID controller are ideal, and the weighting curve of the proportional, integral and differential is shown in Figure 5 (a). The relative value of the output tension curve is shown in Figure 5 (b), and the performance indicators are better than the conventional PID controller. 

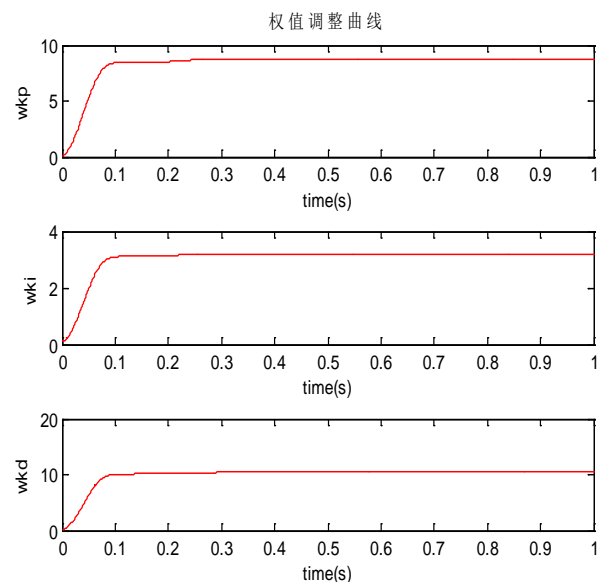

(a)

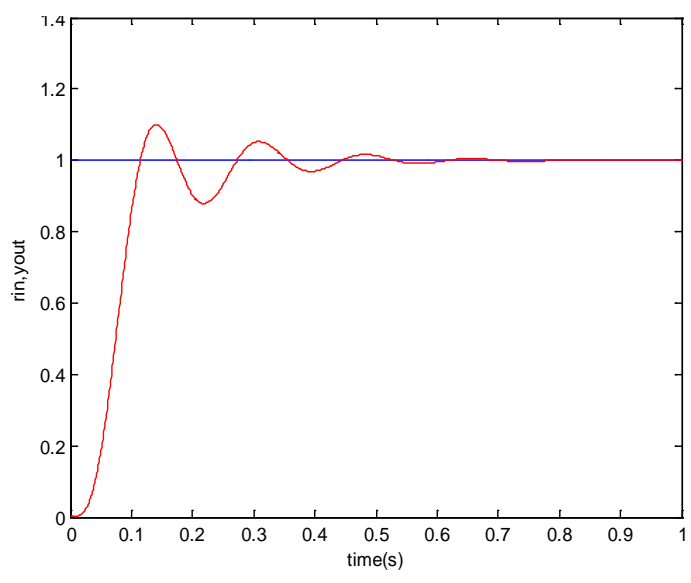

(b)

Figure 5 Single Neuron Adaptive PID weighting factors and output rolling tension curves

It can be seen from the simulation results that single neuron adaptive PID controller allows the controlled object to change within a certain range and has better anti-interference ability. The new controller is essentially a variable coefficient proportional, integral, differential compound controller, and its input is similar to conventional PID controller input. The physical meaning is clear. Its parameters are mainly obtained through online learning with a certain algorithm.

\section{Conclusion}

In this paper, a modeling method of tension control model in cold tandem rolling system is proposed, and single neuron adaptive PID control is successfully applied. The experimental results show that single neuron adaptive PID controller has better adaptive ability to automatically adjust the parameters. As long as appropriate learning parameters are chosen, the system is without overshoot or overshoot is small with no static and strong robust, which can greatly improve the dynamic quality of typical nonlinear time-varying objects, adapt to time-varying characteristics of the controlled process, and ensure that the control system runs in the best condition? It has a wide range of applications in industrial process control.

\section{References}

[1] Song Daojin. Single neuron adaptive PID controller performance optimization [J]. Computer Engineering and Applications, 2005,43 (12): 199 - 201.

[2] Zhang Xueyan, Zhang Jianxia. Single neuron adaptive PID controller and MATLAB simulation [J]. Automation Technology and Applications, 2007, (9): 52-53.

[3] Leandro Dos Santos Coelho and Antonio Augusto Rodigues Coelho. Automatic tuning of PID and gain scheduling PID controllers by a derandomized evolution strategy[J]. Artificial Intelligence for Engineering Design Analysis and Manufacturing. 1999,11(13): 341-349.

[4] Zhang Ying, Li Peng, Wu Wenjiang. Single Neuron PID Sliding Mode Parallel Compound Control for Alternating Current Servo System[J]. Procedia Engineering. 2012, (29):2055-2061.

[5] Yan Peng, Hongmin Liu, R. Du. A neural network-based shape control system for cold rolling operations [J]. Materials Processing Technology. ,2008,(22):54-60. 